\title{
Dangers of Commitment under Rational Expectations
}

\author{
George A. Waters* \\ Department of Economics \\ Campus Box 4200 \\ Illinois State University \\ Normal, IL 61761-4200
}

February, 22, 2010

\begin{abstract}
Within a New Keynesian framework, interest rate rules that respond to public expectations lead to determinate and expectationally stable solutions for any level of commitment, as shown by Waters (2009). That paper also demonstrates gains to commitment, under least square learning, though overcommitment can lead to some very poor outcomes for some parameter values. This paper shows an identical outcome under rational expectations. The optimal level of commitment is unchanged if there are observation errors in the policymaker's knowledge of public expectations, which is not the case under learning. However, if there is sufficient policymaker uncertainty about the parameter values, partial commitment is best.

Keywords: Monetary Policy, Interest Rate Rules, Commitment

JEL classification: E52, E31
\end{abstract}

*gawater@gmail.edu 


\section{Introduction}

Commitment by a monetary policymaker is effective due to its impact on public expectations. Therefore, results about the potential benefits and dangers of commitment could be sensitive to assumptions about the policymaker's knowledge of and the formation of expectations. Waters (2009) studies the gains to commitment in a New Keynesian framework ${ }^{1}$ with forward looking interest rate rules where public expectations are formed by least squares learning, and shows that the modified commitment setting advocated by Blake (2001) and Jensen and McCallum and Jensen (2002) may not be optimal under learning if there are errors in the policy rule. However, one might suspect that this result is independent of learning and is driven by the presence of the errors in the policy rule. The present paper refines these results by studying the same class of interest rate rules under rational expectations.

Interest rate rules that respond to public expectations are studied in Evans and Honkapohja $(2003,2006)$, who show that such rules have the desirable features of determinacy and expectational stability ${ }^{2}$ under both discretion and commitment. Waters (2009) extends their work, reporting determinacy and expectational stability results for a range of commitment levels and simulating the model under least squares learning to find the optimal level of commitment. Commitment ${ }^{3}$ implies that policy must be history dependent, as emphasized by Woodford (1999). The policymaker consistently sets the target rate in response to lagged variables, output in the present context, so that public expectations must take them into account as well. A higher level of commitment corresponds to a larger coefficient on lagged output in the interest rate rule.

Without errors in the policy rule, the behavior of the model under learning and rational expectations is virtually identical. Modified commitment is optimal, but the performance of the policy rule deteriorates rapidly for greater levels of commitment, particularly for a policymaker concerned about output stabilization, as opposed to inflation stabilization. A reasonable conjecture is that the combination of this asymmetry around modified commitment in the policymaker's losses and the policy rule errors implies that modified commitment is not optimal. However, a primary finding of this work is that modified commitment remains optimal under rational expectations, which implies that learning is a necessary condition for the optimality of lesser degrees of commitment.

The asymmetry of the losses for greater levels of commitment does play a role if the policymaker is uncertain about the true parameter values. Simulation with errors in the policy rule due to errors in the estimate of parameter values shows that modified commitment need not be optimal, even under rational

\footnotetext{
${ }^{1}$ The model here is quite standard. Clarida, Gali and Gertler (1999) provide and excellent overview, and Woodford (2003) presents a detailed, micro-founded approach.

${ }^{2}$ See Evans and Honkapohja (2001) for definitions and mathematical exposition of these concepts.

${ }^{3}$ In earlier studies of commitment, such as Barro and Gordon (1983), the inflation bias arises due to the policymaker's desire to push output above the natural rate, but that is not the case here. See Clarida, Gali and Gertler (1999) for a detailed discussion.
} 
expectations. Therefore, a policymaker who adopts history dependent rules must have a high degree of confidence in their model of the economy.

\section{The Model}

The following New Keynesian model has become standard for the study of interest rate rules in monetary policy. It has micro foundations described in Woodford (2003) including price stickiness that allows the policymaker to play a stabilizing role in the economy.

$$
\begin{gathered}
x_{t}=-\varphi\left(i_{t}-E_{t} \pi_{t+1}\right)+E_{t} x_{t+1}+g_{t} \\
\pi_{t}=\lambda x_{t}+\beta E_{t} \pi_{t+1}+u_{t}
\end{gathered}
$$

These equations are expectations augmented IS and Phillip's curve relationships. The variables $x_{t}$ and $\pi_{t}$ are the deviations of output and inflation from their target values. The policymaker controls the nominal interest rate $i_{t}$. The parameters $\varphi, \lambda, \beta$ are all positive and the discount rate $\beta$ is such that $\beta<1$. The stochastic terms $g_{t}$ and $u_{t}$ both have autoregressive structure.

$$
\begin{aligned}
g_{t} & =\mu \widehat{g}_{t-1}+\widetilde{g}_{t}+\widetilde{w}_{t} \\
u_{t} & =\rho u_{t-1}+\widetilde{u}_{t}
\end{aligned}
$$

The parameters $\mu$ and $\rho$ lie in the interval $(-1,1)$, and the shocks $\widetilde{u}_{t}, \widetilde{w}_{t}$ and $\widetilde{g}_{t}$ and are $i i d$ with standard deviations $\sigma_{u}, \sigma_{w}$ and $\sigma_{g}$, respectively. The structure of $g_{t}$ follows McCallum and Nelson (2004) who decompose this term into a preference shock $\widetilde{g}_{t}$ and an $\operatorname{AR}(1)$ process $\widehat{g}_{t}=\mu \widehat{g}_{t-1}+\widetilde{w}_{t}$ that accounts for uncertainty about the evolution of the natural rate that enters into the forecast error for output in the IS equation (1) and represents the portion of the demand shocks about which the public has some information to use for forecasting.

The policymaker sets the nominal interest rate to stabilize the endogenous variables. Formally the task is to set $i_{t}$ to minimize the loss function

$$
L=E_{t} \sum_{s=0}^{\infty} \beta^{s}\left(\pi_{t+s}^{2}+\alpha x_{t+s}^{2}\right)
$$

under rational expectations. The parameter $\alpha$ measures the relative importance of output and inflation 
stabilization for the policymaker. Minimizing the loss function ${ }^{4}$ over $x_{t+s}$ and $\pi_{t+s}$ under the constraint of the Phillip's curve (2) yields the following first order conditions.

$$
\begin{gathered}
E_{t}\left(2 \alpha x_{t+s}+\lambda \omega_{t+s}\right)=0 \quad \text { for } s=0,1,2,3 \ldots \\
E_{t}\left(2 \pi_{t+s}+\omega_{t+s-1}-\omega_{t+s}\right)=0 \quad \text { for } s=1,2,3 \ldots \\
2 \pi_{t}-\omega_{t}=0
\end{gathered}
$$

The variable $\omega_{t+s}$ is the Lagrange multiplier on the constraint for each $s=0,1,2,3 \ldots$. Optimal policy in time $t$ is governed by (7) but policy in succeeding periods is determined by the above condition (6). The time consistency problem is evident since, when the policymaker solves the problem in the period $t+1$, the policy given by (7) will be different than the policy prescribed by (6) in the period $t$ solution.

To find the condition for policy under discretion, the policymaker adopts the optimal policy each period, solving out $\omega_{t}$ for $s=0$ from the first order conditions (5) and (7).

$$
\lambda \pi_{t}+\alpha x_{t}=0
$$

Under discretion, the policymaker takes expectations to be fixed and ignores (6), see Clarida, Gali and Gertler (1999) for a detailed discussion. However, if the policymaker has a "timeless perspective" (Woodford 1999) he or she uses the policy that would have been prescribed in past periods, ignoring condition (7), using (5) and (6) for $s=0$. In this case, which I refer to as full commitment, the policymaker acts to influence future expectations yielding the condition

$$
\lambda \pi_{t}+\alpha\left(x_{t}-x_{t-1}\right)=0 .
$$

Policy under commitment differs from discretion in its response to the previous period's output gap. The reason can be seen in (6), where the lagged term appears because the policymaker reacts to the expected inflation in the Phillip's curve (2). Under discretion, however, the policymaker ignores the change in expected inflation, and lagged output does not enter the policy condition (8). Policy under commitment is equivalent to targeting the price level, meaning that if inflation rises above target, the policymaker will respond by pushing inflation below target for a period of time, as shown in Evans and Honkapoja (2006).

There are several reasons to question full commitment, meaning the policymaker should not be restricted to these extreme cases. First, some agents may not believe the policymaker will commit to a time inconsistent policy. Further, if some public agents are unable to form rational expectations, the gains from commitment

\footnotetext{
${ }^{4}$ The present approach follows Evans and Honkapohja (2006), Woodford (1999b) and Clarida, Gali and Gertler (1999).
} 
could be mitigated, see Waters (2005). If policymakers have incorrect estimates of the model parameters, they could over-react to lagged variables, leading to very poor outcomes.

Furthermore, Blake (2001) argues that the first order condition (6) improperly assumes certainty equivalence and he derives optimal policy that differs from full commitment. Using a version of the loss function (4) without discounting over a finite number of periods, he gives an intuitive argument ${ }^{5}$ for the policymaker to respond to lagged output, but not to the degree indicated by the full commitment condition (9). This approach captures the spirit of the timeless perspective, since including discounting over-emphasizes the loss in initial periods. For these reasons, we consider the general condition

$$
\lambda \pi_{t}+\alpha\left(x_{t}-\kappa x_{t-1}\right)=0 .
$$

The condition under discretion is a special case of (10) where $\kappa=0$, and full commitment is equivalent to setting $\kappa=1$.

The effect of Blake's (2001) approach without discounting is that the second term in (6) is now $\beta \omega_{t+s-1}$. In this case, optimal policy corresponds to the condition (10), where $\kappa$ equals the discount factor $\beta<1$, which I call modified commitment. Woodford (2003) argues in favor of full commitment by using a slightly different criterion than the loss function (4) for evaluating policy. Under rational expectations the optimal level of $\kappa$ is either full commitment at $\kappa=1$ or modified commitment $\kappa=\beta$ depending on the approach to the derivation. I refer to any setting for $\kappa$ such that $0<\kappa<\beta$, when the policymaker's response to lagged inflation is less than for modified commitment, as partial commitment.

\section{Expectations Based Interest Rate Rules}

Evans and Honkapohja $(2003,2006)$ advocate for monetary policy to be conducted with interest rate rules that respond explicitly to public expectations. One can compute the optimal form under rational expectations for the expectations based interest rate rule associated with the policy condition (10). This section also discusses conditions for solutions to be non-explosive, determinate and expectationally stable.

Using (10) to substitute for inflation in the Phillip's curve (2) gives

$$
x_{t}=\lambda\left(\lambda^{2}+\alpha\right)^{-1}\left(\alpha \kappa \lambda^{-1} x_{t-1}-\beta E_{t} \pi_{t+1}-u_{t}\right) .
$$

\footnotetext{
${ }^{5} \mathrm{He}$ also checks the result with a formal derivation. Jensen and McCallum (2002) also discuss this issue. Evans and McGough (2008) refer to this approach as the MJB-alternative in their study of the New Keynsian model with inertia.
} 
Substituting out $x_{t}$ in the IS equation with the above expression yields the interest rate rule

$$
i_{t}=\delta_{L} x_{t-1}+\delta_{\pi} E_{t} \pi_{t+1}+\delta_{x} E_{t} x_{t+1}+\delta_{g} g_{t}+\delta_{u} u_{t}
$$

where the parameters are

$$
\begin{aligned}
& \delta_{L}=-\varphi^{-1}\left(\lambda^{2}+\alpha\right)^{-1} \alpha \kappa, \quad \delta_{\pi}=1+\varphi^{-1}\left(\lambda^{2}+\alpha\right)^{-1} \lambda \beta \\
& \delta_{x}=\varphi^{-1}, \quad \delta_{g}=\varphi^{-1}, \quad \delta_{u}=\varphi^{-1}\left(\lambda^{2}+\alpha\right)^{-1} \lambda .
\end{aligned}
$$

Note that the extent to which the interest rate responds to lagged output, shown by $\delta_{L}$, depends on $\kappa$, but the other parameters in the rule do not. Under discretion, $\kappa$ is zero and $i_{t}$ is unaffected by $x_{t-1}$, but for any other value, including the full, modified and partial commitment settings, the interest rate responds directly to $x_{t-1}$.

The inflation and output expectations in the interest rate rule (11) are determined by the minimum state variables solution of equations (2) and (10). The policymaker reacts to lagged inflation and is able to counteract any demand shock $g_{t}$, so the solutions take the form $x_{t}=b_{x} x_{t-1}+c_{x} u_{t}$ and $\pi_{t}=b_{\pi} x_{t-1}+c_{\pi} u_{t}$. See Waters (2009) for derivation of the solution parameters.

The interest rate rule (11) demonstrates the potential impact of parameter uncertainty on the conduct of policy. For example, if the policymaker's estimate $\varphi_{p}$ is less than the actual $\varphi$, the magnitude of the response of $i_{t}$ to $x_{t-1}$ will be too large, which is equivalent to setting $\kappa$ higher than intended, and simulation results indicate that such a policy could lead to a large loss ${ }^{6}$. For this reason, it is important to study the behavior of the model when $\kappa>1$, even though the policymaker would never knowingly make such a choice. To guard against such a possibility, the policymaker may not fully commit and may choose a smaller response to lagged output than would be indicated by (9).

Interest rate rules corresponding to a value of $\kappa$ greater than one could still have desirable properties of non-explosiveness, determinacy and expectational stability. A solution is non-explosive is $b_{x}<1$.A determinate equilibrium is unique in that there are no other similar equilibria based on extraneous variables. Expectational stability implies that the expectations of agents using a reasonable learning rule converge to the REE. All of these features of interest rate rules are desirable for a policymaker trying to stabilize endogenous variables. The next proposition gives a single condition on $\kappa$ guaranteeing non-explosivesness and determinacy.

\footnotetext{
${ }^{6}$ If the policymaker has a biased estimate of $\lambda$, the change in policy would be equivalent to the change caused by varying the policymaker preference parameter $\alpha$.
} 
Proposition 1 Under rational expectations, for $\kappa$ such that $0 \leq \kappa<1+\frac{\lambda^{2}}{\alpha(1-\beta)}$, the model defined by the policy condition (10) and the Phillip's curve (2) has a determinate, non-explosive and expectationally stable equilibrium.

Proof. See Waters (2009).

The discretionary and full commitment cases of $\kappa=0$ and 1 yield a determinate model, as shown in Evans and Honkapohja (2003, 2006), as do any intermediate values of $\kappa$ including modified and partial commitment, as well as some values of $\kappa>1$.

One might argue that values of $\kappa$ such that $\kappa>1$ are not interesting as there is no justification for such policy. However, as noted above, the policymaker with mistaken estimates of the model parameters could easily overreact to lagged output. The present work uses parameter values from McCallum and Nelson (2004) where $\beta=0.99, \varphi=0.4$ and $\lambda=0.05$. However, other papers in the literature, such as Clarida, Gali and Gertler (2000) and Woodford (1999), use values of $\varphi$ well above one, to give one example of the potential uncertainty about parameter values.

Proposition 1 provides an additional rationale for the appointment of a conservative central banker meaning one with a low weight on output stabilization $\alpha$. Rogoff (1985) shows a conservative central banker can diminish the problem of inflation bias in models where the policymaker wants to raise output above the natural rate. In the present framework, the policymaker cares only about deviations from the natural rate, but a low $\alpha$ may still be desirable since it increases the bound for determinacy and non-explosiveness, making such issues less problematic.

\section{Simulations}

Simulation results for the model described in Proposition 1 show the superiority of modified commitment but also reveal the potential dangers of over-commitment under rational expectations. McCallum and Nelson (2004) study full commitment versus discretionary outcomes for a number of different policy rules under full rationality. They report gains from commitment over discretion for the policymaker for a number of policy rules for varying policymaker preferences regarding output versus inflation stabilization, represented by the parameter $\alpha$ in the present model. The parameters are calibrated so that the time periods correspond to quarterly data. The parameter values that determine the behavior of the stochastic variables $g_{t}$ and $u_{t}$ in (1) and (2) are as follows.

\begin{tabular}{|l|l|l|l|l|}
\hline$\mu$ & $\rho$ & $\sigma_{w}$ & $\sigma_{g}$ & $\sigma_{u}$ \\
\hline 0.95 & 0.8 & 0.005 & 0.02 & 0.005 \\
\hline
\end{tabular}


Figure 1 shows the mean loss, using (4), over 10,000 runs of 200 periods each ${ }^{7}$ for $\alpha \in\{0.01,0.1,0.25,0.5,, 1.0\}$ and $\kappa \in\{0.0,0.1,0.2, \ldots, 1.1,1.2\}$ under rational expectations. Woodford (2003) derives an a loss function of the form (4) from welfare maximization and shows that the optimal value of $\alpha$ must be less than the Phillips Curve parameter $\lambda$, so $\alpha=0.01$ is a reasonable choice by his criteria. The present work follows McCallum and Nelson (2004) in its consideration of higher values of $\alpha$ as well, since they correspond to commonly postulated approaches in the literature. For example, the original Taylor rule puts equal emphasis on inflation and output stabilization, corresponding to $\alpha=0.25$ in this framework.

A primary finding of the present work is that this graph is virtually identical to the one generated when public expectations of output and inflation are generated by least squares learning, shown in Waters (2009). Close examination of the resulting data reveals that the minimum loss is achieved for $\kappa^{*}=0.99=\beta$, for all choices of $\alpha$, so modified commitment is optimal. Further, losses are asymmetric around $\kappa^{*}=\beta$ in that the increase in the losses as $\kappa$ rises above $\beta$ is much worse than if $\kappa$ falls below $\beta$. This observation suggests that it is safer for the policymaker to choose a degree of commitment below modified commitment. However, the asymmetry appears to be less pronounced for lower level of $\alpha$. A more conservative central banker, meaning more concerned about inflation, does not have to be as vigilant about setting $\kappa$ to be too high, implying the same for the response of the interest rate to lagged inflation. Such an observation is not surprising in light the above proposition, which indicates that a higher $\alpha$ increases the bound on $\kappa$ that ensures a non-explosive and determinate equilibrium. These results are all in line with findings from simulations under learning.

\footnotetext{
${ }^{7}$ For all reported results, the loss for each run is calculated over 200 periods after 600 periods for initialization. Since losses are computed with discounting, longer runs do not provide much extra information.
} 
Table 1

\begin{tabular}{|c|c|c|c|c|c|c|}
\hline & & & & $\boldsymbol{\alpha}$ & & \\
\hline & & 0.01 & 0.1 & 0.25 & 0.5 & 1.0 \\
\hline & 0.0 & 0.03592 & 0.11363 & 0.12841 & 0.13294 & 0.13601 \\
\hline & $\beta-0.1$ & 0.01438 & 0.05682 & 0.08176 & 0.09994 & 0.11488 \\
\hline & $\beta-0.5$ & 0.01412 & 0.05301 & 0.07499 & 0.09201 & 0.10674 \\
\hline$\kappa$ & $\beta$ & 0.01411 & 0.05150 & 0.07166 & 0.08660 & 0.10051 \\
\hline & $\beta+0.05$ & 0.01409 & 0.05330 & 0.07716 & 0.09833 & 0.12436 \\
\hline & $\beta+0.1$ & 0.01438 & 0.06001 & 0.09719 & 0.14872 & 0.26593 \\
\hline & Ratios & & & & & \\
\hline & $\frac{L(\kappa=0.0)}{L(\kappa=0.99)}$ & 2.545 & 2.207 & 1.792 & 1.535 & 1.353 \\
\hline & $\frac{L(\kappa=\beta-0.1)}{L(\kappa=\beta+0.1)}$ & 1.000 & 1.056 & 1.189 & 1.488 & 2.315 \\
\hline
\end{tabular}

To quantify the above observations about the optimality of modified commitment the potential dangers of over-commitment, Table 1 reports losses for selected values of $\kappa$, the ratio of the losses under discretion and modified commitment and the ratio of the losses for $\kappa=\beta \pm 0.1$. The former ratio is greater than one and sometime greater than two for varying values of $\alpha$, demonstrating the superiority of modified commitment over discretion. These ratio are similar to those found by McCallum and Nelson (2004), though they were using full, as opposed to modified, commitment with alternative interest rate rules. However, the latter ratio is also greater than one showing that the losses are not symmetric around the modified commitment value $\kappa=\beta$. Losses for $\kappa=\beta+0.1$ are higher than those for $\kappa=\beta-0.1$ so the policymaker should be particularly careful about overcommitting, using an interest rate rule that responds excessively to lagged output. As mentioned above, over-commitment is less of a concern for a low $\alpha$, indicating a more conservative central banker, since their response to lagged output is weaker even under optimal policy. In fact, for $\alpha=0.01$, the ratio of losses for $\kappa \pm 0.1$ is one, which show no such asymmetry.

An important result for the model under learning in Waters (2009) is that the presence of errors in the policymaker's estimates of public expectations can alter the optimality of modified commitment. Replacing $E_{t} x_{t+1}$ with $E_{t} x_{t+1}+\varepsilon_{x, t}$ in the interest rate rule (11) where $\varepsilon_{x, t}$ represents observation errors with variance $\sigma_{x}^{2}$, allows us to compute the losses for simulations with varying magnitude of forecast errors. Since these errors create an additional source of demand shocks $g_{t}$, the variance $\sigma_{g}^{2}$ is lowered for higher $\sigma_{x}^{2}$ such that $\sigma_{g}^{2}+\sigma_{x}^{2}=(0.02)^{2}$. Note that including errors in inflation expectations would have the same effect. 
Table 2

\begin{tabular}{rr|ccccc} 
& & \multicolumn{7}{c}{$\alpha$} \\
& & 0.01 & 0.1 & 0.25 & 0.5 & 1 \\
\hline \multirow{3}{*}{$\sigma_{X}$} & 0.00 & 0.99 & 0.99 & 0.99 & 0.99 & 0.99 \\
& 0.001 & 0.99 & 0.99 & 0.99 & 0.99 & 0.99 \\
& 0.01 & 0.98 & 0.97 & 0.94 & 0.90 & 0.34 \\
& 0.02 & 0.98 & 0.92 & 0.84 & 0.30 & 0.05
\end{tabular}

Table 2 from Waters (2009) shows the loss minimizing setting for $\kappa$, for varying levels of the policymaker's preference parameter $\alpha$ and the standard deviation of the forecasts errors $\sigma_{x}$. For small forecast errors, modified commitment where $\kappa=\beta=0.99$ is best, but for for larger errors the optimal level of $\kappa$ is below $\beta$, significantly so for larger values of $\alpha$ indicated that the policymaker is more concerned about output stabilization.

Under rational expectations, this result is overturned. Modified commitment minimizes the loss in the simulations for all choices of $\alpha$ and $\sigma_{x}^{2}$ in contrast with the results under learning in Waters (2009). The finding for rational expectations indicates that the interaction between the learning rule for public expectations and the errors in the policy rule play a key role in the result that modified commitment represents over-commitment under learning. The inclusion of estimation errors alone does not upset the optimality of modified commitment first identified by McCallum and Jensen (2001) and Blake (2002).

Another issue is whether the asymmetry in the losses across $\kappa$, demonstrated in Table 1, has an impact if the policymaker is uncertain about the true values of the parameters. A policymaker attempting to implement the interest rate rule (11) under modified commitment with a mistaken estimate of a parameter could easily respond over-respond to lagged output, potentially leading to a much higher loss. The estimates of $\phi$ and $\lambda$ vary significantly in the literature, so we study simulations that include an error term with one of these parameters in the interest rate rule (11), for example replacing $\phi$ with $\phi+\varepsilon_{\phi, t}$. Table 3 reports the loss minimizing value of $\kappa$ for varying $\alpha$, the policymaker's preference parameter, and $\sigma_{\phi}$, the standard deviation of the error term $\varepsilon_{\phi, t}$. 
Table 3

\begin{tabular}{cc|ccccc} 
& & \multicolumn{7}{c}{$\alpha$} \\
\hline \multirow{2}{*}{$\sigma_{\phi}$} & & 0.01 & 0.1 & 0.25 & 0.5 & 1 \\
\hline & 0.00 & 0.99 & 0.99 & 0.99 & 0.99 & 0.99 \\
& 0.01 & 0.99 & 0.99 & 0.99 & 0.99 & 0.99 \\
& 0.05 & 0.99 & 0.99 & 0.98 & 0.97 & 0.96 \\
& 0.08 & 0.98 & 0.98 & 0.96 & 0.93 & 0.83
\end{tabular}

Policymaker uncertainty about parameters can impact the optimal level of commitment if the estimation errors are sufficiently large for a policymaker who is insufficiently hawkish about inflation. For larger $a$ 's, the optimal level of $\kappa$ falls below the modified commitment level of 0.99 , and the larger the values of $\alpha$ and $\sigma_{\phi}$ the lower the optimal level of commitment. Table 3 does not show as great a quantitative change in policy, which is largely due to the difficulty in obtaining reliable results for larger values of $\sigma_{\phi}$. Since the errors enter multiplicatively, larger shocks have a dramatic impact on the losses, and the optimal values vary. Similarly, errors in the estimate of the parameter $\lambda$ have a definite impact on optimal policy, but reliable quantitative results are difficult to obtain.

The quantitative importance of parameter uncertainty deserves further investigation. As noted, the parameter estimates vary significantly in the New Keynesian literature, much more than is represented by the error terms in the simulations reported here. Evans and Honkapohja (2000) has a stability analysis of the situation where both public agents and policymakers are updating their estimates of model parameters with a learning mechanism. Simulations to determine optimal policy in such an environment is an important area for future work.

\section{Conclusion}

There are clear advantages to commitment for a monetary policymaker in the present context where a forward looking interest rate rule responds to lagged output and thereby influences public expectations. Waters (2009) shows that such rules have non-explosive, determinate and expectationally stable solutions for a wide range of responses to lagged output. That paper also demonstrates that modified commitment is optimal under least squares learning, but the losses to the policymaker are skewed toward higher levels of commitment. Furthermore, with errors in the policy rule, modified commitment is no longer optimal under learning. 
Under rational expectations, modified commitment remains optimal with or without policy errors. Hence, the contrary result under learning arises due to the interaction between the learning mechanism and the errors in the policy rule. However, the asymmetry of the losses around modified commitment is present under rational expectations, particularly for policymakers who are concerned about output stabilization. Therefore, if there is uncertainty about the precise response to lagged output indicated by modified commitment, arising from uncertainty about model parameters for example, it may be prudent for the policymaker to choose a weaker level of commitment, even assuming rational expectations.

\section{References}

Barro, Robert J. and David B. Gordon (1983) A Positive Theory of Monetary Policy in a Natural Rate Model. Journal of Political Economy 91, 589-610.

Blake, A. P. (2001) A 'Timeless Perspective' on Optimality in Forward-Looking Rational Expectations Models. Working Paper, National Institute for Economic and Social Research.

Clarida, Richard and Jordi Gali and Mark Gertler (1999) The Science of Monetary Policy: A New Keynesian Perspective. Journal of Economic Literature 37, 1661-1707.

Clarida, Richard and Jordi Gali and Mark Gertler (2000) Monetary Policy Rules and Macroeconomic Stability: Evidence and Some Theory. Quarterly Journal of Economics 115, 147-180.

Evans, George and Seppo Honkapohja (2001) Learning and Expectations in Macroeconomics. Princeton University Press, Princeton, NJ.

Evans, George and Seppo Honkapohja (2003) Expectations and the Stability Problem for Optimal Monetary Policies. Review of Economic Studies 70, 807-824.

Evans, George and Seppo Honkapohja (2006) Monetary Policy, Expectations and Commitment. Scandinavian Journal of Economics 108, 15-38.

Evans, George and Bruce McGough (2006) Optimal Constrained Interest Rate Rules. Journal of Money, Credit and Banking, forthcoming.

Evans, George and Bruce McGough (2008) Implementing Optimal Monetary Policy in New-Keynesian Models with Inertia. working paper.

Jensen, Christian and Bennet McCallum (2002) The Non-Optimality of Proposed Monetary Policy Rules Under Timeless-Perspective Commitment. Economics Letters, 77(2), 163-168.

McCallum, Bennet T. (1983) On Non-uniqueness in Linear Rational Expectations Models: An Attempt at Perspective. Journal of Monetary Economics 11, 139-168.

McCallum, Bennet T. and Edward Nelson (2004) Timeless Perspective vs. Discretionary Monetary Policy in Forward Looking Models. Federal Reserve Bank of St. Louis Review 86(2), 43-56..

Walsh, Carl E. (2003) Monetary Theory and Policy. MIT Press, Cambridge, MA.

Waters, George A. (2005) Dangers of Commitment: Monetary Policy with Adaptive Expectations. Journal 
of Economics and Finance 30(1),93-104.

Waters, George A. (2009) Learning, Commitment and Monetary Policy. Macroeconomic Dynamics 13(4), $421-449$.

Woodford, Michael (1999) Commentary: How Should Monetary Policy Be Conducted in an Era of Price Stability? In New Challenges for Monetary Policy, pp. 277-316, Federal Reserve Bank of Kansas City.

Woodford, Michael (2003) Interest and Prices. Princeton University Press, Princeton, NJ. 


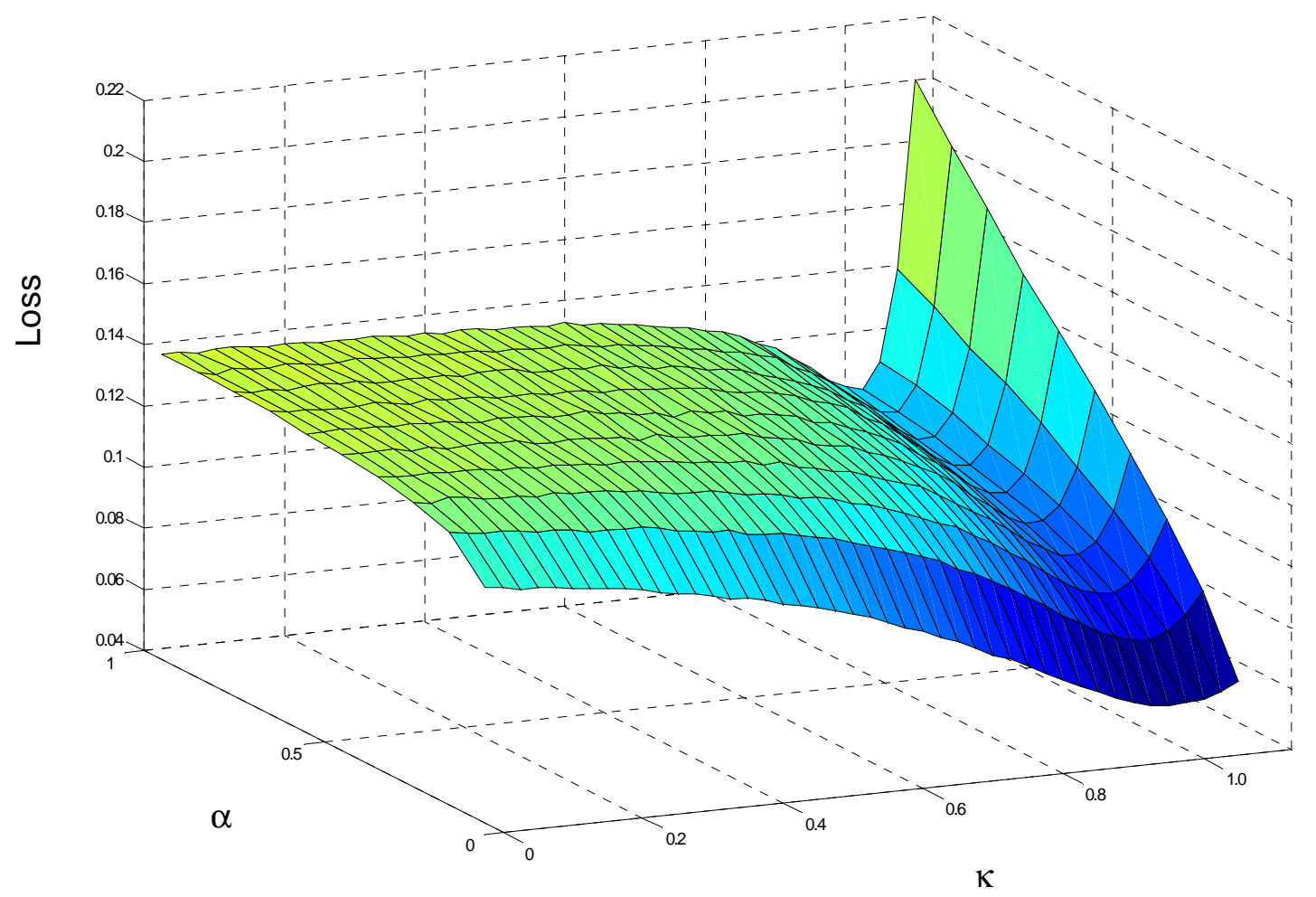

Figure 1: Mean loss over 10,000 runs for each pair $(\alpha, \kappa)$. 